\title{
Short Communication: Effect of Feed Barrier Design on the Behavior of Loose-Housed Lactating Dairy Cows
}

\author{
M. I. Endres, ${ }^{1}$ T. J. DeVries, ${ }^{2}$ M. A. G. von Keyserlingk, ${ }^{2}$ and D. M. Weary ${ }^{2}$ \\ ${ }^{1}$ Department of Animal Science, University of Minnesota, St. Paul 55108 \\ ${ }^{2}$ Animal Welfare Program, The University of British Columbia, 2357 Main Mall, \\ Vancouver, BC, V6T 1Z4, Canada
}

\section{ABSTRACT}

The objective of this study was to evaluate the effects of 2 feed barrier systems on feeding and social behavior of dairy cows. Forty-eight lactating Holstein cows were subjected to each of 2 treatments in a cross-over design. The treatments were 2 types of feed-line barriers: 1) post-and-rail, and 2) headlock. Time-lapse video was used to quantify the feeding behavior and incidence of aggressive displacements of the cows at the feed bunk. Average daily feeding time did not differ when cows used the headlock barrier compared with the post-andrail barrier. However, there were certain changes in feeding time during periods of peak feeding activity: cows that had lower feeding times relative to group mates when using the post-and-rail barrier showed more similar feeding times to group mates when using the headlock barrier. There were $21 \%$ fewer displacements at the feed bunk when cows accessed feed by the headlock barrier compared with the post-and-rail barrier. These results suggest that using a headlock barrier reduces aggression at the feed bunk and improves access to feed for socially subordinate cows during peak feeding periods.

(Key words: feed barrier, feeding behavior, dairy cow)

Fence-line feeding is common for loose-housed cows at commercial dairies. This feeding system was conceived to allow access to feed while preventing the animals from walking and defecating on the feed. However, the design of the physical barrier separating the cows from the feed may also have unintended consequences, such as limiting the cows' ability to freely access feed and increasing the frequency of aggressive interactions at the feeder.

Increased aggressive interactions at the feeder are thought to limit access to feed, especially during peakfeeding times (Friend and Polan, 1974). In previous

Received February 9, 2005.

Accepted April 7, 2005.

Corresponding author: Marcia Endres; e-mail: miendres@umn. edu. research, we showed that increasing space allowance at the feeder reduces competition and improves access to feed, particularly for subordinate cows (DeVries et al., 2004). The design of the feeding facility is known to have profound effects on feeding competition in other farm animals (e.g., Andersen et al., 1999). For cattle, which often displace one another when feeding by swinging and butting with the head, modifications that restrict head and neck movements may be particularly effective in reducing competition and improving access to feed.

Bouissou (1970) found that divisions at the feeder separating the heads of adjacent individuals allowed subordinate cows to feed for longer periods of time. Many modern free stall and drylot dairies use headlocks as a feed barrier. These headlocks provide divisions between the necks of adjacent cows and have a manually activated self-locking feature that can be used to restrain animals. Some previous researchers (e.g., Batchelder, 2000; Brouk et al., 2003) compared headlocks to more open feed-line barriers, but these researchers reported variable results, used limited treatment replicates, and did not address the effects of feedline barrier on the feeding and social behavior of cows. Thus, the objective of the current study was to determine if a feed-line barrier that provides physical separation between the necks of adjacent cows allows for increased feeding times, particularly at the time of peak feeding activity, and a reduction in aggressive behavior at the feed bunk.

Eight primiparous and 40 multiparous lactating Holstein dairy cows were used in this study. Animals were housed in 4 pens in a free-stall barn at The University of British Columbia Dairy Education and Research Center (Agassiz, British Columbia, Canada) and were managed according to the guidelines set by the Canadian Council on Animal Care (1993). Each experimental pen (width $=7.32 \mathrm{~m}$ and length $=13.50 \mathrm{~m}$ ) contained 12 free stalls (deep bedded with sand) configured in 3 rows. The feed line area of each pen was $7.32 \mathrm{~m}$ wide. When the pens were fitted with the post-and-rail barrier, the rail was supported by 3 posts $(0.1 \mathrm{~m}$ in diameter) that were $3.66 \mathrm{~m}$ apart (on center), providing 0.60 
$\mathrm{m}$ of feeding space per cow. When the pens were fitted with the headlock barrier, there was 1 headlock per cow. Each headlock measured $0.61 \mathrm{~m}$ in width, having a $0.18 \mathrm{~m}$ wide opening for the neck of the cow, and a $0.43 \mathrm{~m}$ separation between the necks of adjacent cows. No cows were restrained in these headlocks at any time during the study. A TMR formulated to meet the NRC (2001) nutrient requirements of high-producing dairy cows was fed ad libitum for the entire experiment. The TMR contained, on a DM basis, $15.7 \%$ corn silage, $11.6 \%$ grass silage, $10 \%$ grass hay, $8.4 \%$ alfalfa hay, $17.2 \%$ flattened corn and barley mix, and $37.1 \%$ concentrate mix. Animals were fed daily at approximately 0600 and $1530 \mathrm{~h}$. Feed was pushed up closer to the cows at 1100 and $2200 \mathrm{~h}$ daily to ensure that feed was available to the cows during all hours of the day. The animals were milked twice daily at approximately 0600 and $1700 \mathrm{~h}$.

Samples of the TMR and orts were taken twice during each period and analyzed for DM, NDF, and $\mathrm{CP}$ at a commercial laboratory (Norwest Laboratories, Lethbridge, Alberta, Canada) using standard AOAC methods. The DMI for each group for each day on treatment were calculated by subtracting the DM weight of the orts from the DM weight of the fresh feed. Diet NDF and $\mathrm{CP}$ averaged 35.5 and $17.6 \%$, respectively, and concentrations were similar between periods and pens. The orts NDF and CP averaged 38.2 and $17.2 \%$, respectively, and the daily orts averaged $6.6 \pm 3.6 \%$ (mean \pm $\mathrm{SD}$ ) of the fresh feed provided over the course of the experiment.

The 48 cows were divided into groups of 12 , balanced by parity $(2.9 \pm 1.9$; mean $\pm \mathrm{SD})$, projected 305 -d milk production $(10,977.9 \pm 1919.3 \mathrm{~kg})$, and DIM (113.9 \pm $33.1 \mathrm{~d}$ ), and assigned to 1 of 2 starting conditions: access to the feed bunk via a post-and-rail barrier or via a headlock barrier in a $2 \times 2$ cross-over design. During the first period, cows were kept for $8 \mathrm{~d}$ on one treatment ( $2 \mathrm{~d}$ of adjustment and $6 \mathrm{~d}$ of data collection). The feed barriers were then switched between pens, and cows were then kept on the alternative treatment for a second 8-d period.

Feeding and social behavior data were collected using 1 video camera (Panasonic WV-BP330; Osaka, Japan) per pen, a time-lapse videocassette recorder (Panasonic AG-6540), and a video multiplexer (Panasonic WJ-FS 216). The video cameras were located $6 \mathrm{~m}$ above the feed bunk of each pen. Red lights ( $100 \mathrm{~W})$, hung adjacent to the cameras, were used to facilitate recording at night. Animals were marked with unique alphanumeric symbols made with hair dye on the back to allow for individual cow identification when watching the video recordings.

Feeding behavior data were collected from continuous 24 -h video recordings using 10 -min scan sampling.
In preliminary analyses we correlated 1 -min video observations with various scan intervals $(2,3,5,7,10$, $15,25,30$, and $60 \mathrm{~min}$ ) and found near-perfect correlations $(r>0.95)$ for all scan intervals of 10 min or less, indicating that 10-min scans could be used to adequately and efficiently capture information on feeding behavior. For each scan, an animal was recorded as feeding when its head was completely past the feed barrier and over the feed. These scans were then used to calculate the daily time spent feeding by multiplying the daily number of scans by 10 . These scans were also used to calculate the feeding time during the 90-min periods following the delivery of feed when feeding activity was highest.

The number of displacements from the feed bunk per day was collected by continuous observation of $24-\mathrm{h}$ video for the last $3 \mathrm{~d}$ of recording for each treatment condition. A displacement was considered to occur when 1 cow ("the actor") contacted another ("the reactor") anywhere along the front half of its body (from the pelvis cranially), causing the reactor to immediately remove its head completely from the feed barrier (DeVries et al., 2004).

For tests of the effect of treatment on DMI, daily feeding time, feeding time during the 90 min after feed delivery, and displacements from the feed bunk, the pen was considered the experimental unit with measures from multiple days and cows averaged to create 1 observation per pen per treatment. Treatment effects on all measures were tested by paired $t$-tests with 3 degrees of freedom. To test the prediction that cows would respond differently to the headlock treatment, depending upon their ease of access to feed when using the post-and-rail barrier, feeding times during the 90 min after feeding for the 2 treatments were compared using linear regression with the cow as the observational unit. Specifically, to determine if cows changed on average, the intercept was tested for difference from 0 , and to determine the extent of the change relative to the initial value, the slope was tested for difference from 1.

Dry matter intake was not affected $(\mathrm{t}=0.02, P=$ 0.98 ) by treatment, averaging $25.7 \pm 0.7 \mathrm{~kg}$ per cow per day for both treatments. This result agrees with Brouk et al. (2003) who also reported no differences in pen DMI in an on-farm study comparing headlocks and post-andrail barriers. Additionally, average feeding time did not differ ( $\mathrm{t}=1.12, P=0.34$ ) when cows had access to the feed by the headlock barrier $(271.8 \pm 3.8 \mathrm{~min} / \mathrm{d}$; mean $\pm \mathrm{SE}$ ) compared with the post-and-rail barrier (277.8 \pm $3.8 \mathrm{~min} / \mathrm{d}$ ). However, as illustrated in Figure 1, during periods of peak feeding activity (90 min after feed delivery), there were fewer cows at the feed bunk when using the headlock barrier. Cows spent an average of $47.9 \mathrm{~min}$ 


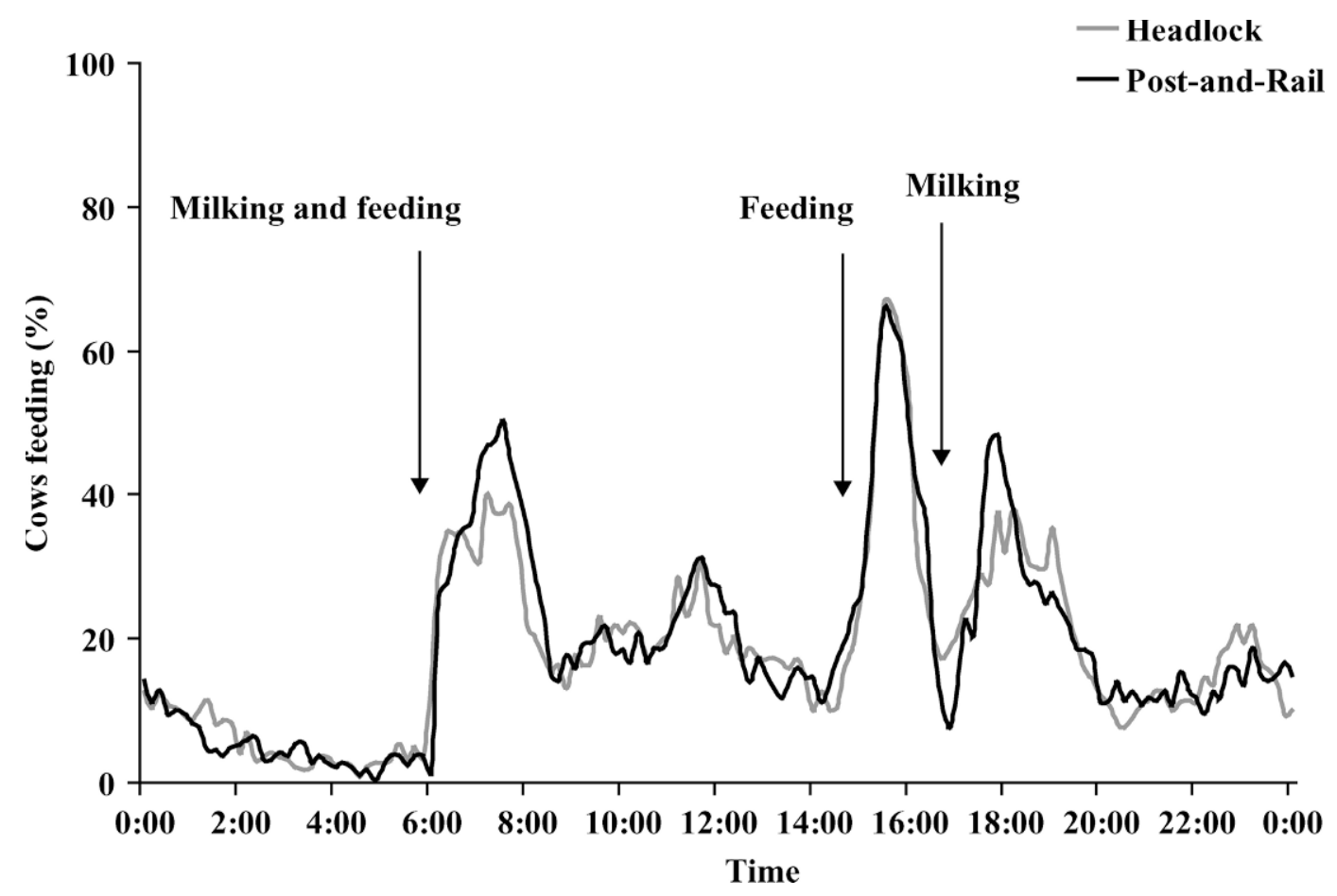

Figure 1. Percentage of cows per group present at the feed bunk over a 24-h period for cows accessing feed through either headlock or post-and-rail feed-line barriers. Data were averaged for $6 \mathrm{~d}$ per treatment of 4 groups of 12 cows each.

feeding during these periods when using the headlock barrier compared with $52.0 \mathrm{~min}$ when using the postand-rail barrier $(t=2.87, \mathrm{SE}=1.0 ; P=0.005)$. Feeding times during periods of peak feeding activity were highly related for the 2 treatment conditions (Figure 2; $\left.\mathrm{R}^{2}=0.65, P<0.001\right)$. The slope $(0.78 \pm 0.09)$ for the linear relationship was significantly $<1\left(\mathrm{~F}_{1,46}=6.48\right.$, $P=0.01)$, and the intercept $(7.09 \pm 4.58)$ was not significantly greater than $0\left(\mathrm{~F}_{1,46}=2.39, P=0.13\right)$. Thus, cows with lower feeding times relative to group mates when using the post-and-rail barrier showed more similar feeding times to group mates when using the headlock barrier. This result agrees with Bouissou (1970), who reported that divisions at the feeder separating the heads of side-by-side individuals allowed subordinate cows better access to feed. Cook et al. (2004) suggest that dominant cows sort fresh feed, and that low-ranking cows with low feed access may be forced to alter daily activity patterns and feed at the bunk only after dominant cows have accessed the fresh feed. Therefore, providing equal access to fresh feed may be particularly important in reducing the variation in diet quality consumed by the cows.

Cows performed fewer aggressive interactions at the feed bunk when using the headlock compared with the post-and-rail barrier (5.5 vs. 6.9 displacements per cow per day; $\mathrm{t}=3.85, \mathrm{SE}=0.3 ; P=0.03)$. Researchers have also demonstrated that partitions between pigs at the feed trough reduce aggression and displacements when feeding (Baxter, 1986; Andersen et al., 1999). The current study is the first to show that using a feed-line barrier with partitions between adjacent dairy cows can reduce aggression at the feed bunk. Unfortunately, aggressive behavior still occurred when using the headlock barrier, indicating that the neck division does not provide full protection. Bouissou (1970) found that divisions at the feeder separating the entire heads or bodies of side-by-side individuals allowed subordinate cows to feed for longer periods of time compared with when no division was used. This suggests that using head or body divisions between adjacent cows may further reduce the frequency of aggressive interactions at the feed bunk.

In conclusion, there was no difference in overall feeding time between the 2 barriers, but the headlock barrier allowed for more equal access to feed for cows during peak feeding periods. Use of a headlock barrier also reduced the frequency of aggressive interactions at the feed bunk. These aggressive interactions are known to increase with stocking density (e.g., DeVries et al., 2004), so in the future, researchers should examine the effects of barrier design in relation to stocking rate. Moreover, we encourage further work examining the 


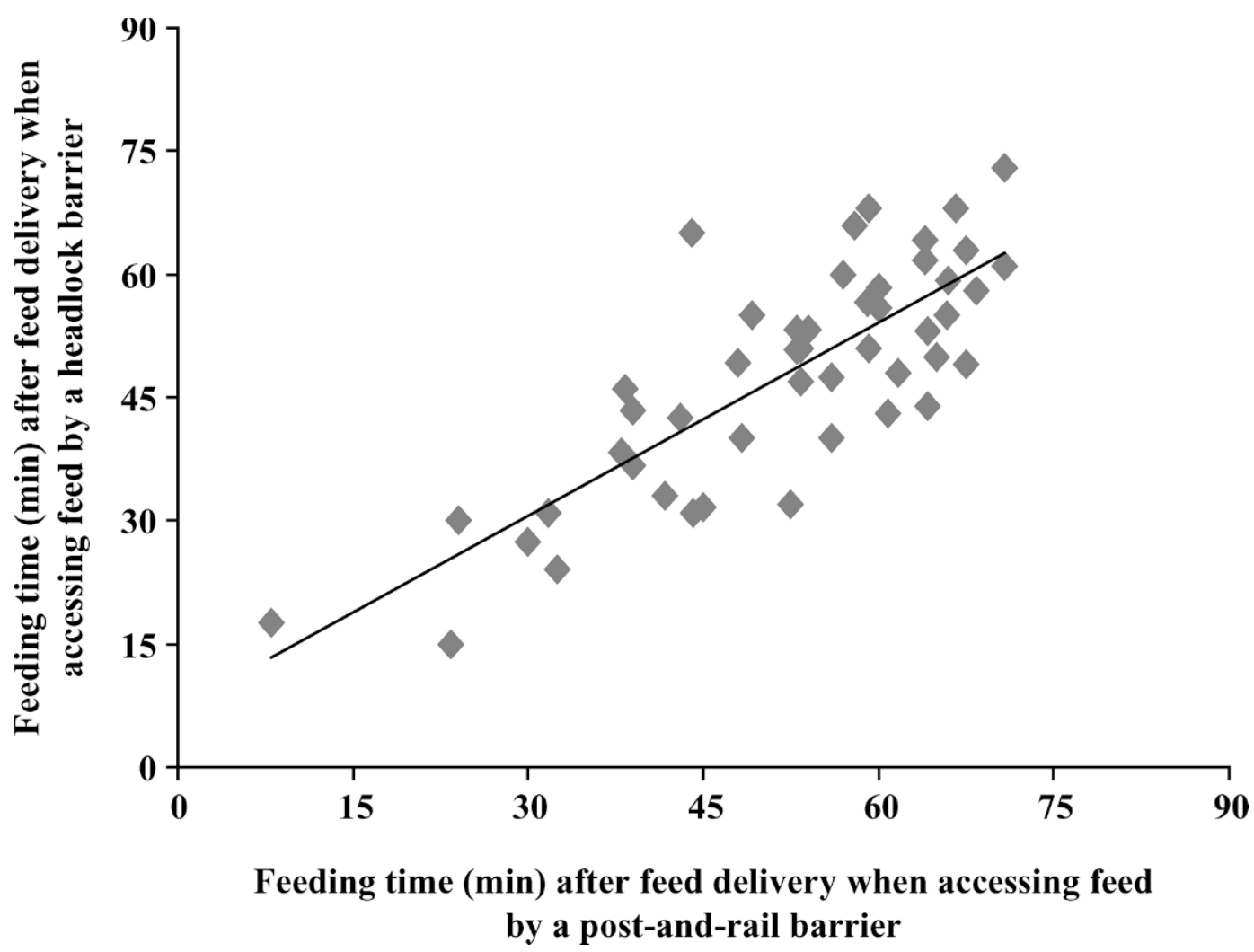

Figure 2. The relationship between feeding time during 90 min following feed delivery when cows accessed feed by a post-and-rail barrier vs. a headlock barrier. Feeding time was averaged for $6 \mathrm{~d}$ per treatment of 48 cows (4 groups of 12), fed twice daily.

effects of using head and body dividers to further reduce aggression at the feed bunk.

\section{ACKNOWLEDGMENTS}

We thank the staff and students at The University of British Columbia's Dairy Education and Research Centre and the University's Animal Welfare Program. In particular we thank Kiyomi Ito for her help with the video analysis. The project was funded by the Natural Sciences and Engineering Research Council of Canada, through the Industrial Research Chair in Animal Welfare, and by contributions from the Dairy Farmers of Canada, the BC Dairy Foundation, the BC SPCA, members of the BC Veterinary Medical Association, and many other donors listed on the Animal Welfare website at http://www.agsci.ubc.ca/animalwelfare.

\section{REFERENCES}

Andersen, I. L., K. E. Boe, and A. L. Kristiansen. 1999. The influence of different feeding arrangements and food type on competition at feeding in pregnant sows. Appl. Anim. Behav. Sci. 65:91-104
Batchelder, T. L. 2000. The impact of head gates and overcrowding on production and behavior patterns of lactating dairy cows. Pages 325-330 in the Proceedings of the 2000 Dairy Housing and Equipment Systems: Managing and planning for profitability. NRAES-129, Ithaca, NY.

Baxter, M. R. 1986. The design of the feeding environment for the pig. Ph.D. Thesis, University of Aberdeen, UK.

Bouissou, M.-F. 1970. Role du contact physique dans la manifestation des relations hierarchiques chez les bovines. Consequences pratiques. Ann. Zootec. 19:279-285.

Brouk, M. J., J. F. Smith, and J. P. Harner, III. 2003. Effect of feedline barrier on feed intake and milk production of dairy cattle. Pages 192-195 in Proc. 5th Int. Dairy Housing Conf. K. A. Janni, ed. American Society of Agricultural Engineers, St. Joseph, MI.

Canadian Council on Animal Care. 1993. Guide to the Care and Use of Experimental Animals. Vol. 1. E. D. Olfert, B. M. Cross, and A. A. McWilliam, ed. CCAC, Ottawa, Canada.

Cook, N. B., K. V. Nordlund, and G. R. Oetzel. 2004. Environmental influences on claw horn lesions associated with laminitis and subacute ruminal acidosis in dairy cows. J. Dairy Sci. 87(E. Suppl.):E36-E46.

DeVries, T. J., M. A. G. von Keyserlingk, and D. M. Weary. 2004. Effect of feeding space on the inter-cow distance, aggression, and feeding behavior of free-stall housed lactating dairy cows. J. Dairy Sci. 87:1432-1438.

Friend, T. H., and C. E. Polan. 1974. Social rank, feeding behavior, and free stall utilization by dairy cattle. J. Dairy Sci. 57:12141220.

National Research Council. 2001. Nutrient Requirements for Dairy Cattle. Natl. Acad. Sci., Washington, DC. 